\title{
ENGENHEIROS, INDÍGENAS E OPERÁRIOS: OS MALFADADOS CAMINHOS DA ESTRADA DE FERRO MADEIRA-MAMORÉ (1870-1883)
}

\author{
ENGINEERS, INDIGENOUS AND WORKERS: THE MALFATED \\ PATHWAYS OF THE MADEIRA-MAMORÉ RAILWAY (1870-1883)*
}

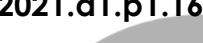

\section{Antonio Alexandre Isidio Cardoso'}

\begin{abstract}
Resumo
A construção da Estrada de Ferro Madeira-Mamoré (EFMM) é uma das páginas mais trágicas da história amazônica. Entre indígenas, operários e engenheiros foram erigidos travosos conflitos e desafios de alteridade, enredados na complexa relação com as territorialidades do rio Madeira no século XIX. O presente estudo tem o objetivo de discutir alguns elementos desse cenário histórico a partir do escrutínio de jornais, fontes oficiais e narrativas de viagem. A base analítica principal da proposta perpassa a leitura de um relatório de engenheiros viajantes, que estruturaram a Comissão Morsing. O grupo foi responsável por sondar as possibilidades de execução da obra da estrada de ferro na floresta, que à época já havia sido abandonada duas vezes. A viagem da comitiva rendeu um pormenorizado relatório em 1883, no qual podem ser lidas narrativas sobre as experiências e estranhamentos dos engenheiros nos sertões amazônicos, com foco na estadia em Santo Antônio no rio Madeira.
\end{abstract}

Palavras-chave: Amazônia; Rio Madeira; Comissão Morsing.

\begin{abstract}
The building of the Madeira-Mamoré Railway (EFMM) hold tragic pages in Amazonian history. Among indigenous peoples, workers and engineers, violent conflicts and otherness challenges were erected, entangled in the complex relationship with the territorialities of the Madeira River. This article aims to discuss some elements of this historical plot based on the scrutiny of newspapers, official documents and travel narratives. The main analytical basis of this study goes through the reading of a report written by traveling engineers, who joined the Morsing Commission. The group published a detailed report in 1883, describing their travel, focusing on their experiences at the EFMM site in Santo Antônio at the Madeira River.
\end{abstract}

Keywords: Amazon; Madeira River; Morsing Commission.

\footnotetext{
* Artigo organizado a partir de reflexões da tese de doutoramento "O Eldorado dos Deserdados: indígenas, escravos, migrantes, regatões e o avanço rumo ao oeste amazônico no século XIX”. O trabalho foi defendido na Universidade de São Paulo em 2018, com bolsa da Fundação de Amparo à Pesquisa do Estado de São Paulo - FAPESP.

* Article organized based on reflections from the doctoral thesis "O Eldorado dos Deserdados: Indians, slaves, migrants, regatões and the advance towards the western Amazon in the 19th century". The work was defended at the University of São Paulo in 2018, with a grant from the Research Support Foundation of the State of São Paulo - FAPESP.

1 Professor adjunto da Universidade Federal do Maranhão (UFMA), colegiado de Ciências Humanas/História, Campus Codó. Doutor em História Social pela Universidade de São Paulo (USP), com estágio de pesquisa na New York University (NYU). E-mail: alexandre.antonio@ufma.br
} 


\section{Prelúdios}

A construção da Estrada de Ferro Madeira-Mamoré (EFMM) faz parte do rol das tentativas fracassadas de submissão da Amazônia aos interesses do capital. Entre a década de 1870 e a sua inauguração em 1912, foram consumidas milhares de vidas de trabalhadores nacionais e estrangeiros. Desde o início, o empreendimento ignorou especificidades ecológicas locais, que somadas aos complexos desafios de alteridade da floresta conformaram um cenário ambientalmente e socialmente catastrófico² ${ }^{2}$

O Tenente Coronel George Earl Church foi o primeiro a tentar articular a EFMM. Suas ações tiveram íntima relação com o desencadeamento dos interesses norteamericanos em terras amazônicas, fortalecidos desde a década de $1850^{3}$. Sua ideia era fixar o caminho de ferro às margens do rio Madeira, varando as matas para evitar um extenso trecho encachoeirado, afamado pela difícil navegação. Em 1872, uma comitiva de 25 engenheiros norte-americanos foi contratada para avaliar a localidade de Santo Antônio, escolhida como base do projeto ${ }^{4}$. O terreno era desconhecido do grupo estrangeiro, instruído com saberes alheios às peculiaridades locais. $\mathrm{O}$ resultado final foi malfadado, acumularam-se conflitos, doenças e mortes, potencializadas pela inadequação dos conhecimentos técnicos dos engenheiros na lida com a floresta.

Após alguns anos de abandono, seria a vez de um poderoso grupo de empreiteiros yankees entrarem na disputa pela EFMM. Os irmãos Philip e Thomas Collins, representantes da $P . \& T$. Collins, empresa de construção sediada na Filadélfia, deram continuidade à obra. Os empresários almejaram introduzir inicialmente 1500 operários, vindos de diversos países e também de outras províncias do Império brasileiro. Segundo levantamento feito por Gary Van Valen, o empreendimento começou em 1878 com 300 bolivianos (entre os quais muitos indígenas) e um grupo misto que contava com 500 operários, entre americanos e italianos. No mesmo ano, 120 italianos desertaram da obra,

\footnotetext{
${ }^{2}$ HARDMAN, Francisco Foot. Trem Fantasma: a ferrovia Madeira-Mamoré e a modernidade na selva. São Paulo: Companhia das Letras, 2005.

${ }^{3}$ Conferir: SAMPAIO, Maria Clara Sales Carneiro. A Amazônia no olhar imperialista: a história ainda pouco explorada do projeto do norte-americano Matthew Fontaine Maury para a Amazônia na década de 1850. Canoa do Tempo: Revista do Programa de Pós-graduação em História da Universidade Federal do Amazonas. v. 11 n. 01 (2019).

${ }^{4}$ FORTE, Ernesto Mattoso Maia. Do Rio de Janeiro ao Amazonas e Alto Madeira. Itinerário e Trabalhos da Comissão de Estudos da Estrada de Ferro do Madeira e Mamoré: Impressões de Viagem por um dos membros da mesma comissão. Rio de Janeiro: Typ. a Vap. de Soares \& Niemeyer, 1885. p.7
} 
e uma nova remessa foi contratada, dessa vez formada por trabalhadores oriundos da Província do Ceará 5 .

Esses migrantes enfrentaram pagamentos atrasados, desavenças internas, alimentação precária e sobretudo incontáveis perdas ocasionadas por "febres palustres", como a malária e a febre amarela. Mesmo assim, sob a batuta dos irmãos Collins, os obreiros executaram até o final dos anos 1870 os primeiros quilômetros do projeto, que mais uma vez foi paralisado diante da escalada de mortes, investidas de indígenas e acumulação de prejuízos.

\section{Comissão Morsing}

Foi a partir da confirmação da segunda desistência que o poder central no Rio de Janeiro iniciou movimentações para avaliar as possibilidades de retomar a obra. Foi criada a Comissão Morsing ${ }^{6}$, chefiada pelo experimentado engenheiro Carlos Alberto Morsing, que já havia atuado em trabalhos em outras províncias, como no caso da Estrada de Ferro de Baturité, no Ceará ${ }^{7}$. O objetivo da nova comitiva era sondar o que havia restado e o que poderia ser aproveitado das duas primeiras desventuradas tentativas de execução do projeto. Ernesto Mattoso Maia Forte, secretário da comissão, deixou registrado em seu relatório em 1883 alguns testemunhos de tensões em face da obra, destacando inicialmente o estranhamento ante a presença de "selvagens".

Na noite de 13 para 14 de maio o acampamento da $2^{a}$ sessão foi visitado pelos índios Acangas-Pirangas. Desde às 8 horas da noite mais ou menos, as sentinelas diziam ter visto vultos pelas matas em redor. Ninguém, porém, quis dar crédito. Entretanto às 2 horas da madrugada, ouviu-se a detonação de alguns tiros dados ao mesmo tempo. Alarmou todo o acampamento.

Foi então que se pôde ver os tais visitantes noturnos, que corriam para a mata fazendo infernal alarido.

As sentinelas sentindo-os perto dispararam as armas para assim despertar a todos, visto ignorarem quantos seriam a acometer-nos.

$\mathrm{O}$ engenheiro Leitão da Cunha em companhia de dois soldados, embrenhou-se na espessa floresta a ver se conseguia falar com os naturais, mas foram baldadas as tentativas.

\footnotetext{
${ }^{5}$ VALEN, Gary Van. Indigenous agency in the Amazon: The Mojos in liberal and Rubber-Boom Bolivia. Tucson: The University of Arizona Press, 2013. p.79

6 Detalhamento da comissão: "Por portaria de 25 de novembro foram dadas as devidas instruções à comissão e nomeado o seu pessoal na ordem que se segue: engenheiro chefe Carlos Alberto Morsing; primeiro engenheiro, Julio Pinkas, Chefes de sessão, Abel Ferreira de Mattos e Domingos Guilherme Braga Torres; secretário, Ernesto Mattoso Maia Forte; engenheiros-condutores, Pedro Leitão da Cunha, Alfredo de Freitas Reis, Damaso Pereira, Candido Ferreira de Abreu, Thomaz Joaquim de Cerqueira e Alfredo Índio do Brazil e Silva; médico Dr. F. Betim Paes Leme; farmacêutico, José da Fonseca e Silva, desenhador, Camillo Vedani, e auxiliares, João Martins da Silva e José Coelho Ferreira Junior.” FORTE, Do Rio de Janeiro ao Amazonas e Alto Madeira....op.cit. p. 15

${ }^{7}$ Cf. CÂNDIDO, Tyrone Apollo Pontes. Proletários das secas: arranjos e desarranjos nas fronteiras do trabalho. Fortaleza: Universidade Federal do Ceará, Tese de Doutorado em História, 2015.
} 
(...)

Até o dia 14 de maio, quando apareceram os índios Acangas-Pirangas tivemos um trabalhador encarregado somente de arranjar caça para os doentes; mas dessa data em diante por dinheiro nenhum quis correr o risco de encontrar-se frente a frente e só diante de tão cruéis inimigos ${ }^{8}$.

Desde antes da viagem os excursionistas já conheciam boatos sobre a gravidade do cenário local. Os jornais da Corte vinham divulgando informações sobre os travosos caminhos das tentativas de construção da EFMM. As notícias de mortes de trabalhadores, precariedade na obtenção de alimentos, desavenças com indígenas, dissenções internas, inadaptações do projeto, entre outras dificuldades, circulavam por todo o Império.

O terror infundido pelos Acanga-Piranga era uma das faces do descompasso entre a estrada de ferro e a floresta. Ao ouvirem alaridos de guerra não havia quem se arriscasse, "por dinheiro nenhum", adentrar o território ocupado pelos indígenas para conseguir comida ou mesmo remédios para os doentes. Nas margens do rio Madeira o acesso aos recursos das matas, como a caça, a pesca, as frutas, era nitidamente regulado pelos habitantes locais, conformados por diversos povos, como Parintintin, Caripuna, Arara e os próprios Acanga-Piranga ${ }^{9}$.

\section{Vertigem do vazio}

Os planos da EFMM não contemplavam a existência dos possíveis atingidos pela obra. A modernidade não previa a convivência com indígenas, no limite imaginados sob o viés romantizado do século XIX. Correrias e gritos de guerra provavam de maneira traumática a incômoda e incisiva presença das populações nativas. Engenheiros e indígenas forçosamente encaravam-se nas situações de contato, aceleradas no curso das tentativas de construção da estrada de ferro.

Ao chegarem em Santo Antônio, os emissários da Comissão Morsing descobriram que não poderiam escapar das tensões de ordem social assentadas naquele braço da frente de expansão no rio Madeira ${ }^{10}$. A Amazônia passava por uma crescente devassa de seus

\footnotetext{
8 FORTE. Do Rio de Janeiro ao Amazonas e Alto Madeira...op.cit. pp. 156;164

9 Sobre o histórico e a diversidade das paisagens ameríndias do rio Madeira, conferir: AMOROSO, Marta Rosa. Guerra mura no século XVIII: versos e versões: representações dos Mura no imaginário Colonial. Campinas, Universidade Estadual de Campinas, dissertação de mestrado em Antropologia, SP, 1991; LEAL, Davi Avelino. Direitos e Processos diferenciados de territorialização: os conflitos pelo uso dos recursos naturais no Rio Madeira (1831-1932). Manaus, Universidade Federal do Amazonas, Tese de Doutorado em Sociedade e Cultura da Amazônia, 2013.

10 MARTINS, José de Souza. Fronteira: a degradação do outro nos confins do humano. São Paulo: Contexto, 2009. O autor entende frente de expansão como fenômeno demográfico que guarda sua historicidade em estreito contato com a definição de fronteira. No caso do surto extrativista no século XIX
} 
altos rios. Desde a criação da Província do Amazonas, implementada em 1852, foram estruturadas medidas mais incisivas de esquadrinhamento do território. A nova unidade do Império tinha pressa em aferir as possibilidades de exploração de seus rios e florestas, facilitada pela introdução de linhas regulares de navegação a vapor, que aceleraram a circulação de pessoas e mercadorias. Esse novo expansionismo, em parte decorrente do incremento tecnológico, maximizou interesses econômicos internacionais, que à época eram capitaneados pela demanda industrial por borracha, crescentemente explorada na planície amazônica ${ }^{11}$.

Francisco Foot Hardman assevera que empreitadas semelhantes estavam acontecendo em diversas áreas do globo. O capitalismo expansionista encarnava a civilização fundada na sociedade industrial, a qual devia preencher todos os espaços do globo com seus "pacíficos" interesses:

Era preciso, pois, dar nome às armas desse enorme empreendimento de conquista, pôr a engenharia militar a serviço da taxinomia do progresso e tornar legíveis os pontilhados mais minúsculos do mapa-múndi. Os poderes saídos da fábrica tinham seu próprio arsenal de signos. Faziase mister desfraldar suas bandeiras até nos recantos mais obscuros e inóspitos. Com efeito, haveria de vencer a vertigem do vazio, exatamente à custa de outra miragem forjada pelos trilhos, pelas quimeras de ferro ${ }^{12}$.

Diferentemente da época das grandes navegações, sob o filtro dos preceitos cristãos e do trabalho de conversão de pagãos, a edificação das quimeras de ferro era dessacralizada. Sobre os trilhos do progresso oitocentista eram os engenheiros os verdadeiros missionários. No Brasil, estes tiveram atuação decisiva no processo de interiorização durante o Segundo Reinado, planificando diversas obras cujos relatórios documentaram facetas dos sertões do país, deixando entrever, para além da execução das modernas obras, elementos de paisagens sociais distantes da Corte.

Não por acaso, engenheiros ganharam espaço nos quadros da burocracia do Império. A Real Escola Militar, fundada em 1810 no Rio de Janeiro, foi responsável pela formação de várias gerações desses profissionais. Segundo Maria Helena P. T. Machado, na formação em engenharia eram combinados conhecimentos de ordem científica e

na Amazônia, também estudado por Martins, a população passou a se deslocar para áreas de forte atuação da empresa extrativista, mas não simplesmente como "massa" trabalhadora, e sim enquanto agentes que também ajudavam a estabelecer (e até ressignificar) a Frente de Expansão.

11 SANTOS, Roberto Araújo de Oliveira. História econômica da Amazônia. 1800- 1920. São Paulo: Queiroz, 1980.

${ }^{12}$ HARDMAN, Francisco Foot. Trem Fantasma: a ferrovia Madeira-Mamoré e a modernidade na selva. São Paulo: Companhia das Letras, 2005. p. 129. 
prática, cabendo ao "oficial militar e ao oficial engenheiro enfrentar os enormes desafios colocados pelas dimensões territoriais e os obstáculos instransponíveis que se antepunham na realização de uma missão civilizatória em paragens remotas"13.

Seguindo tal tendência, o relatório da Comissão Morsing produziu várias pistas que extrapolavam seu conteúdo eminentemente cartesiano, excedendo a dimensão técnica da empreitada. O secretário da expedição anotou detalhes sobre o deslocamento de fronteiras ${ }^{14}$, inscrito no crescente movimento de embarcações a vapor, diretamente interligado à construção da estrada de ferro. Durante a travessia da bacia amazônica, ainda antes de chegada ao destino final, não foram poucos os registros de movimentações de pessoas com destino às cabeceiras do rio Madeira. No trecho entre Manaus e Santo Antônio, o vapor da comitiva de engenheiros tomou alguns "passageiros de ré", rebocados em suas canoas, que se encaminhavam para o trabalho nos seringais da região.

No dia 9 chegamos a Canumã às 2 horas da tarde e saímos às 4 . Aí tomamos alguns passageiros de ré e uma turma de índios Mundurucus, que foram para Humaitá trabalhar em seringais.

São eles mansos, de boa aparência e muito amigos dos brancos a ponto de baterem-se por eles (...). É opinião corrente que eles fizeram pacto de amizade com os antigos governadores e pela sua dedicação não é difícil crer-se.

Entre eles vinha um índio Mura, de mais de cem anos de idade, mas ainda trabalhador, excessivamente escuro e feio. $\mathrm{O}$ dedo grande do pé direito é enormemente separado dos outros pela continuação (sic) de aí colocar o arco quando tem de flechar. Traziam todos grande porção de flechas e arcos para a caça e para a pesca e bem assim cada um trazia o seu cão, a que dão grande estimação, apesar de lhes darem pouco de comer $^{15}$.

$\mathrm{Na}$ ocasião, duas diferentes vertentes da situação de fronteira se uniam dentro do vapor Cametá ${ }^{16}$. A primeira, mais antiga, representava os circuitos produtivos ligados à

\footnotetext{
${ }^{13}$ MACHADO, Maria Helena P. T. Brasil a vapor: raça, ciência e viagem no século XIX. São Paulo, Universidade de São Paulo; Tese apresentada para o concurso de Livre Docência, 2005. p.110

${ }^{14}$ Movimento em direção aos altos rios da bacia amazônica, instrumentalizado desde o período colonial em demanda dos limites ocidentais do território lusitano na floresta. Tal movimentação ganhou amplitude na segunda metade do século XIX, especialmente após a criação da Província do Amazonas, a qual se associou ao incremento da navegação a vapor e o interesse sobre produtos extrativistas, em especial a borracha. Sobre o tema, conferir: SANTOS, Francisco Jorge dos. Nos Confins Ocidentais da Amazônia Portuguesa: mando metropolitano e a prática do poder régio na Capitania do Rio Negro no século XVIII. Manaus: Tese de Doutorado em Sociedade e Cultura na Amazônia, Universidade Federal do Amazonas, 2012; BASTOS, Carlos Augusto de Castro. No Limiar dos Impérios: projetos, circulações e experiências na fronteira entre a Capitania do Rio Negro e a Província de Mainas (1780-1820). Tese de Doutorado em História Social - USP, São Paulo, 2013.

${ }^{15}$ FORTE,. Do Rio de Janeiro ao Amazonas e Alto Madeira...op.cit. p.72.

${ }^{16}$ A situação de fronteira tinha relação direta com os encontros e desencontros dos envolvidos na frente de expansão. Desse modo, os processos de transculturação, ou seja, de cruzamento de costumes, línguas e visões de mundo (nem sempre de maneira harmônica) podem ser considerados peças chave para a
} 
extração de drogas da floresta, naquele momento conectados com a exploração de seringais ${ }^{17}$. A segunda, bem mais recente, simbolizava o projeto técnico encarnado no grupo de engenheiros, que nesse momento estava em sintonia com os interesses nacionais e estrangeiros que deram impulso à EFMM. O entendimento dessas camadas de sentido deve ser tratado como componente fundamental para analisar os movimentos da frente de expansão interna amazônica. Conforme aponta estudo clássico de João Pacheco de Oliveira, é imprescindível "dar conta dos tempos e ritmos diferenciais" basilares num contexto no qual temporalidades e leituras de mundo dissonantes se encaravam ${ }^{18}$.

Os Mundurucu e o velho Mura, tidos como "mansos" e "amigos dos brancos", tinham atrás de si séculos de complexas negociações e conflitos pelos sertões amazônicos. Seus povos foram "pacificados" nos tempos da Colônia, firmando posteriormente negócios com brancos, incluso alianças de guerra que ajudaram no alargamento dos domínios portugueses na floresta ${ }^{19}$. Esse retrospecto estava relacionado com a trajetória das conquistas coloniais, atualizadas no século XIX com modernos interesses expansionistas. Entre indígenas e engenheiros havia temporalidades que ensejavam diálogos de diferentes regimes de historicidade. Inadvertidamente, os índios estavam encarando no vapor uma nova faceta da exploração de seus territórios, numa bricolagem que combinava o arbítrio de corporações capitalistas e as demandas de agentes do poder central do Império, comprometidos com o ideário civilizatório oitocentista.

Naquele momento os membros da Comissão Morsing tinham diante de si sociabilidades antigas e pouco conhecidas para homens cultos oriundos da Corte. Indígenas "mansos", trabalhadores do cotidiano extrativista, supostamente aculturados, representavam largas parcelas de populações amazônicas, mas passavam longe do quadro

compreensão dos desafios de alteridade que ajudavam a conformar as situações de fronteira no território amazônico oitocentista. Cf. GRANERO, Fernando Santos, BARCLAY, Frederico. La Frontera Domesticada: História econômica y social de Loreto. 1850-2000. Lima: Ed. Pontifica Universidad Católica Del Peru, 2002; PRATT, Mary Louise. Imperial Eyes: travel writing and transculturation. London and New York: Routledge, 1992.

${ }^{17}$ Sobre os circuitos produtivos indígenas na Amazônia Ocidental, conferir: SANTOS, Gilton Mendes dos e APARÍCIO, Miguel. Redes Arawa: ensaios de etnologia do Médio Purus. Manaus: EDUA, 2016.

${ }^{18}$ OLIVEIRA, João Pacheco de. O Caboclo e o Brabo: Notas sobre duas Modalidades de Força de Trabalho na Expansão da fronteira Amazônia no século XIX. Encontros com a Civilização Brasileira, 1979, v. 10, p. 106.

19 Sobre especificidades históricas sobre os povos Mura e Mundurucu, conferir: AMOROSO, Marta Rosa. Guerra mura no século XVIII...op.cit. e HARRIS, Mark. Rebellion on the Amazon: The Cabanagem, Race, and Popular Culture in the North of Brazil, 1798-1840. New York, Cambridge University Press, 2010. 
demográfico que seria encontrado em Santo Antônio ${ }^{20}$. A acepção que classificava Mundurucu e Mura como amigos dos brancos não era generalizável para a situação de fronteira desenhada a partir da construção da estrada de ferro. As águas e as populações do rio Madeira se mostrariam também bravas aos engenheiros vindos do Rio de Janeiro ${ }^{21}$.

\section{Mundos do trabalho no rio Madeira}

Muito antes da chegada da expedição ao destino já existiam copiosos registros de contendas. A convivência entre indígenas, negociantes e representantes oficiais da Província do Amazonas mostrava-se bastante tensa, e com a elevação das movimentações direcionadas ao Madeira esse quadro tornou-se ainda mais travoso. As notícias sobre violências e mortes quase sempre tinham relação com o malfadado destino de obreiros nacionais e estrangeiros mobilizados para a estrada de ferro. Tal quadro ganhava ares dramáticos quando havia conflitos entre estes e as populações indígenas que defendiam seus territórios.

Em 1874 a Falla do Presidente da Província, Domingos Monteiro Peixoto, mostrou preocupação com as "correrias" indígenas contra os operários, à época ainda sob a gerência dos norte-americanos. Na tentativa de solucionar o problema, Peixoto convocou o Capitão de Artilharia Emigdio Cavalcante de Mello, "nomeado pelo Governo Imperial a 25 de agosto do ano próximo findo, membro da comissão de fortificações de fronteira desta província”. O militar foi deslocado para o rio Madeira com a atribuição de eleger o terreno mais propício para a "construção de um quartel, que possa conter pelo menos duzentos praças e que tenha acomodações suficientes para a respectiva oficialidade" 22 . Sem o controle pleno do curso do rio e temendo a possibilidade de ruína do mais importante empreendimento do interior, a autoridade máxima do Amazonas literalmente anunciou uma frente de guerra contra os indígenas "selvagens" do Madeira.

$\mathrm{Na}$ área já existia um destacamento militar que guardava os limites do rio com o território boliviano. Contudo, os recrutas enfrentavam difíceis condições de

\footnotetext{
${ }^{20}$ Sobre a ideia do indígena "manso", conferir: BALESTRA, Aline Alcarde. O que significa ser "manso"? A selvageria e a civilização sob diferentes perspectivas. In. DOS SANTOS, Gilton Mendes e APARÍCIO, Miguel. Redes Arawa...op.cit.

${ }^{21}$ A expressão "águas bravas" foi pensada a partir de reflexões do Historiador Eurípedes Funes, que utiliza o termo para definir as difíceis rotas de fuga em demanda da liberdade de escravos fugidos na Amazônia. Cf. FUNES, Eurípedes A. "Nasci nas matas, nunca tive senhor" - História e Memória dos Mocambos do Baixo Amazonas. São Paulo. Universidade de São Paulo; Tese de doutorado em História Social, 1995.

${ }^{22}$ Falla dirigida à Assembleia Provincial do Amazonas em 25 de março de 1874 pelo Presidente da Província Domingos Monteiro Peixoto. Disponível em: http://brazil.crl.edu/bsd/bsd/83/000051.html (último acesso 31/08/2020).
} 
sobrevivência, compartilhando com os operários da EFMM vários dos infortúnios vivenciados nos trabalhos da obra. Não eram incomuns notícias de trabalhadores flechados ou desaparecidos. Em 1879 o Barão de Maracajú, então mandatário do Amazonas, lamentou em sua Falla a ocorrência de mais um desses episódios. Dessa vez, os atingidos foram alguns trabalhadores cearenses:

No ponto militar de Santo Antonio do Rio Madeira, no mês de novembro do ano passado, foram flechados pelos índios AcangaPiranga três cearenses a serviço da estrada de ferro do Madeira e Mamoré, tendo um destes falecido em decorrência do ferimento que recebera. O Subdelegado do respectivo distrito acompanhado de alguns praças do destacamento foi no encalço daqueles selvagens e conseguiu afugentar, visto se terem logo internado nas matas ${ }^{23}$.

Migrantes vindos do Ceará chegavam em terras amazônicas desde antes do início da execução do projeto do EFMM. O fluxo tinha base em múltiplas razões de migração, com destaque para as redes de contato familiares que vinham se constituindo em consonância com o avanço rumo ao oeste amazônico. Além do eixo principal destinado aos altos rios, com destaque para os seringais, os destinos desses obreiros também tinham outras vertentes. Muitos aportavam (ou desertavam de seus contratantes) ao longo da subida dos rios, arranjando-se nas florescentes capitais amazônicas. As idas e vindas de Paroaras, apelido dado aos homens que recrutavam trabalhadores, tiveram papel de destaque na concatenação dessas movimentações, como intermediários que levavam um ideário de opulência da Amazônia até suas vilas de origem no Ceará ${ }^{24}$.

O período da seca de 1877-1879 tornou os fluxos de trabalhadores já existentes ainda mais expressivos. Os irmãos Collins visualizaram no aumento das movimentações uma possibilidade de drenar parte do contingente de migrantes para a EFMM. Um dos colaboradores dos empreiteiros estadunidenses já havia residido em Fortaleza, dado que lhe conferia conhecimento sobre o caráter atrativo das terras amazônicas e os canais prévios de arregimentação de migrantes no Ceará. Foi nesse ensejo que José Paulino von Hoonholtz tornou-se uma espécie de Paroara, conseguindo arregimentar grande número de cearenses, posteriormente destinados a Santo Antônio. Segundo estudo de Tyrone

\footnotetext{
${ }^{23}$ Falla com que o Exmo. Sr. Barão de Maracaju, Presidente da Província do Amazonas, no dia 29 de março de 1879 abriu a $2^{\mathrm{a}}$ Sessão da $14^{\mathrm{a}}$ Legislatura da Assembleia Legislativa Provincial. Disponível em: http://brazil.crl.edu/bsd/bsd/90/000003.html (último acesso, 31/08/2020)

${ }^{24}$ Para mais referências sobre a trajetória de Paroaras, conferir: CARDOSO, Antonio Alexandre Isidio. Nem sina, Nem acaso: a tessitura das migrações entre a Província do Ceará e o território amazônico. Fortaleza, Universidade Federal do Ceará, Dissertação de Mestrado em História Social, 2011.
} 
Apollo Pontes Cândido, “dos seiscentos embarcados, quinhentos eram contratados como trabalhadores, vinte homens iam como apontadores de turmas e quarenta mulheres (esposas dos operários) foram como cozinheiras. Completando o grupo estavam quarenta crianças" 25 .

A heterogênea caravana de migrantes vivenciou todas as problemáticas da travessia, marcada pela superlotação da embarcação, alimentação escassa, estranhamentos diante das novas terras, dentre outros fatores, que paulatinamente iam desbotando as imagens edênicas da floresta, convertida para muitos em inferno verde ${ }^{26}$. Depois da longa viagem, conforme aponta pesquisa de Edson Holanda Lima Barboza, “ao chegarem em Santo Antônio o andamento da obra já estava comprometido. Os atrasos no envio de financiamentos provocaram irregularidades nos pagamentos dos operários, empreiteiros e fornecedores (...)"27.

Além dos problemas indicados por Barboza, os migrantes ainda teriam de encarar travosas relações com os indígenas da área. Contratados como parte dos esforços modernizantes, os operários recém-chegados adentraram o mundo social da floresta sem mediadores, experimentando as rusgas da situação de fronteira de maneira abrupta. Os Acanga-Piranga aparecem em vários registros dessas tensões, fazendo incursões à área de construção da estrada, atacando operários, avançando até mesmo em direção ao território sob a guarda do destacamento militar local ${ }^{28}$.

Outros povos que habitavam o rio Madeira também eram apontados como responsáveis por ações semelhantes, com destaque para os Parintintin, Arara e Caripuna. De acordo com estudo de Davi Avelino Leal, esses povos "fizeram no século XIX uma dura guerra contra as invasões de suas áreas de reprodução física e cultural" ${ }^{29}$. Esse cenário de lutas intestinas comprometia não só a EFMM, mas também os interesses de seringalistas e outros exploradores que viam seus negócios inviabilizados face à resistência ameríndia. Por isso, de acordo com Leal, para além do Estado, quem liderou

\footnotetext{
${ }^{25}$ CÂNDIDO, Tyrone Apollo Pontes. Proletários das secas...op.cit. p. 44.

${ }^{26}$ A referência a ideia do "inferno verde" foi constituída em contraponto ao imaginário de opulência da floresta, que teve grande notoriedade na conformação dos fluxos migratórios de cearenses para o território amazônico no século XIX. Um autor em particular, que publicou obra intitulada "Inferno Verde", ajudou a concatenar essas representações a partir da literatura no início do século XX. Cf. RANGEL, Alberto. Inferno Verde (Scenas e Scenários do Amazonas). Tours: Typografia Arrault e Ca, 1927.

${ }^{27}$ BARBOZA, Edson Holanda Lima. A Hidra Cearense: rotas de retirantes e escravizados entre o Ceará e as fronteiras do Norte. São Paulo, Pontifícia Universidade Católica; Tese de Doutorado em História. p.181 28 HDBN. Amazonas, 5 de novembro de 1879, n.348, p.3

${ }^{29}$ LEAL, Davi Avelino. Direitos e Processos diferenciados de territorialização: os conflitos pelo uso dos recursos naturais no Rio Madeira (1831-1932). Manaus, Universidade Federal do Amazonas, Tese de Doutorado em Sociedade e Cultura da Amazônia, 2013. p.141
} 
as ofensivas contra "selvagens" foram poderosas famílias interessadas em controlar áreas de prolíficos seringais e castanhais, situados em domínios indígenas ${ }^{30}$.

Ainda no que se refere ao contato com "bravios", havia, além da guerra, a preocupação com a conservação de garantias mínimas para a manutenção da produção local, o que forçava a abertura de negociações no sentido de evitar os recorrentes ataques advindos dos habitantes das matas. Na tentativa de abrir canais de diálogo, os patrões paulatinamente introduziram mercadorias e ferramentas nas redes de trocas dos indígenas refratários, almejando torná-los fregueses. Qualquer empreitada que se somasse ao deslocamento de fronteiras deveria ter em consideração os liames desse cenário, situado entre o conflito e a mediação, baseado na construção de intercâmbios socioeconômicos e culturais no rio.

\section{Violência e servidão}

O relato deixado pelos membros da Comissão Morsing revela notas bastante elucidativas dos problemas decorrentes da inaptidão em lidar com as paisagens sociais do Madeira. Sob a pressão dos muitos revezes, a expedição foi abrindo espaço para o registro de detalhes que iam além dos conflitos e dos problemas enfrentados na viagem.

No que se refere à relação entre indígenas e patrões, o relatório dedicou um capítulo inteiro aos "hediondos crimes que reduziam índios à escravidão" 31 . O secretário Maia Forte arrolou uma série de exemplos da prática da servidão por dívida desdobradas em várias formas de privação de liberdade. A sujeição era lastreada pelo sistema de aviamento, uma modalidade de relação econômica sustentada pelo endividamento dos trabalhadores, que, desprovidos de salários, recebiam alimentos, ferramentas, roupas, dentre outros gêneros, em troca dos produtos conseguidos na floresta. Esse sistema também estava atrelado ao transporte de trabalhadores, a quem posteriormente eram cobrados os encargos da viagem, pagos em borracha ${ }^{32}$. Segundo o testemunho, a ocorrência desses casos era acompanhada de muita violência, incluindo açoitamentos e até mesmo assassinatos. Havia um clima de ameaça contra quem tentasse escapar das teias de controle e do pagamento das dívidas. Muitos dos submetidos aos regimes de

\footnotetext{
${ }^{30}$ LEAL. Direitos e Processos diferenciados de territorialização... op. cit. p.171

${ }^{31}$ FORTE. Do Rio de Janeiro ao Amazonas e Alto Madeira...op.cit. p. 137.

32 WEINSTEIN, Bárbara. A borracha na Amazônia: expansão e decadência, 1850-1920. São Paulo: HUCITEC: Editora da Universidade de São Paulo, 1993.
} 
servidão eram indígenas advindos da Bolívia, principalmente Mojos e Baures, distribuídos nos seringais do Madeira ${ }^{33}$.

Diante desse quadro de horrores, Maia Forte traçou um breve paralelo entre a instituição escravista e as formas de trabalho análogas à escravidão no rio Madeira, cogitando que alguns povos indígenas dos altos rios viviam agruras piores que as de algumas das populações negras escravizadas no Sul do Império, pois estas recebiam alimentação e vestuário às custas de seus senhores, diferente de índios privados da liberdade, que contraíam dívidas para satisfazer os mesmos intentos.

\section{Considerações finais: cotidiano e desafios de alteridade}

Como se vê, o contexto social documentado pela Comissão Morsing revela bem mais que os reveses da EFMM. O relatório do grupo de engenheiros produziu pistas sobre o panorama da frente de expansão oitocentista, com elementos que vão além da aventura da modernidade na "selva". A menção às condições de trabalho das populações indígenas deixa entrever os inevitáveis desafios ante um mundo social pouco conhecido, enredado em conflitos e negociações seculares entre sociedades locais e o avanço de interesses colonialistas.

Do Rio de Janeiro até Santo Antônio no rio Madeira houve mais que um deslocamento de milhares de quilômetros dentro do Brasil. No percurso, diferentes regimes de temporalidade se encontraram, atualizando o repertório histórico da situação de fronteira. A narrativa produzida pela Comissão Morsing, inicialmente vislumbrada como uma mirada técnica sobre a construção da estrada de ferro, levantou diversas informações sobre facetas de um Brasil profundo. Chamaram a atenção do grupo de engenheiros aspectos dos mundos do trabalho e também do cotidiano de populações que viviam no interior da Província do Amazonas.

Esse foi o caso da festividade de São Tomé, registrada entre o povo Turá. Na opinião do secretário da comissão de engenheiros essa era uma reminiscência dos tempos de maior presença de religiosos no Madeira, quando estes introduziram um calendário em honra aos santos católicos entre os nativos. Na descrição da cerimônia de São Tomé, Maia Forte observou que a festividade era toda celebrada em Nheengatu, língua forjada por Jesuítas à época colonial com base no Tupi, largamente utilizada no trabalho de catequese

\footnotetext{
${ }^{33}$ VALEN. Indigenous agency in the Amazon...op.cit.
} 
na Amazônia ${ }^{34}$. Na ocasião, duas velhas matriarcas capitaneavam a solenidade, segurando "um grande arco enfeitado de folhas e flores silvestres", percorrendo a maloca entoando “cânticos à mãe de Deuss3.

A inserção dessa narrativa no meio de números e dados quantitativos empresta ao relato da Comissão Morsing ainda mais complexidade. Nessa mesma direção, uma das mais intrigantes anotações sobre o cotidiano local trata da trajetória de um dos filhos de um casal de negociantes, conhecido como João Arara. Esse personagem foi o único sobrevivente de uma ofensiva indígena ocorrida numa praia do rio Aripuanã, afluente do Madeira. Na ocasião, a família estava fazendo um giro comercial pelo interior, barganhando suas mercadorias. Em certa altura, um grupo de nativos desconhecidos investiram contra o casal, executando ambos e capturando seu filho pequeno.

Segundo o relatório, em pouco tempo a notícia do fatídico evento se espalhou e os índios Arara, que eram parceiros comerciais da família atacada, organizaram uma contraofensiva, declarando guerra ao povo que havia sequestrado a criança. Depois de alguns dias de combate finalmente conseguiram vencer os contrários, tomando o menino de volta. Mas, ao invés de ser devolvido aos seus parentes "brancos”, João passou a viver entre os Arara.

Embora vivesse aparentemente como um igual, não tinha licença para ausentar-se dos domínios controlados pelos índios. Com o passar do tempo, João auferiu grande influência, tornando-se Tuхаиа, uma liderança entre os Arara. Somente após longos anos pôde aproveitar uma temporada de celebrações e bebedeiras para se ausentar, abandonando seus protetores e engajando-se como seringueiro nos percursos da frente de expansão no Madeira. Segundo o registro dos engenheiros, o caso era bastante conhecido nas localidades de Manicoré e Borba. João Arara era facilmente identificado por ainda conservar na face grafismos que o distinguiam como pertencente ao povo indígena ${ }^{36}$.

Conquanto o apontamento seja longo, vale a pena reproduzir alguns trechos do testemunho, tendo em conta sua riqueza em detalhes.

João Arara, cujos pais viviam em Borba, quando criança acompanhouos a uma viagem que fizeram à praia da pripioca, junto ao Rio Aripuanã, a fim de colherem ovos de tartaruga e negociarem com uma tribo selvagem, com quem estavam em relações de comércio havia já algum

\footnotetext{
${ }^{34}$ FREIRE, José Ribamar Bessa. Da Língua Geral ao Português: para uma História do uso social das línguas na Amazônia. Rio de Janeiro, Tese de Doutorado em Literatura Comparada, Universidade do Estado do Rio de Janeiro, 2003.

${ }^{35}$ FORTE,. Do Rio de Janeiro ao Amazonas e Alto Madeira... op.cit. p.129.

${ }^{36}$ FORTE,. Do Rio de Janeiro ao Amazonas e Alto Madeira...op.cit p. 79.
} 
tempo. Chegados a esse lugar, quando ia a noite bem alta já, foram atacados por um bando numeroso de gentios desconhecidos que assassinaram pai e mãe e levaram consigo a infeliz criança.

Os Araras, tribo que com eles comerciavam, ao terem notícia do ocorrido, deram-se pressa em guerrear a outra tribo até que conseguiram tomar a criança. O infeliz João foi por eles criado e por vezes escapou à morte, por não habituar-se à alimentação que lhe davam. Venceu, porém, todas estas dificuldades e conseguiu alcançar o posto de Tuxaua. (...)

Um dia celebrava-se com toda a pompa uma das festas costumadas. Havia chiça e cachiry em abundância, os tambores de pau (trocanos) já anunciavam o princípio da embriaguez; batiam, rufavam e os selvagens riam, cantavam, gritavam e alegres folgavam entre a felicidade da inconsciência e as delícias do ébrio. No dia seguinte, exaustos todos de cansaço, e como de costume, recolheram-se todos para dormir e reabilitarem as forças perdidas. João tinha necessidade de procurar flechas e prepará-las para a caça e para a guerra, saiu, pois com suas duas esposas e foi cortá-las em um lugar longe onde haviam-nas melhores e mais fortes.

Uma das mulheres, cansada do festim, adormecera enquanto ele cortava as flechas, e outra se entranhara pelo flechal também ajudando o esposo. João (foi) cada vez mais se embrenhando pelo mato até que chegara à beira de um largo e volumoso igarapé justamente na ocasião em que passava uma canoa com duas ou três pessoas que se dirigiam a Itacoatiara, e a ela pediu passagem ${ }^{37}$.

Tendo conta o caso de João Arara, é preciso salientar que o relatório produziu pistas sobre (des)encontros culturais conectados com dimensões sócio-históricas pouco evidenciadas em outros documentos. Além de um fenômeno de ordem econômica e demográfica, a devassa dos altos rios acionava uma série de possibilidades de interação cultural, que vinham se constituindo bem antes e à revelia do impulso modernizante da estrada de ferro. Ao fim e ao cabo, as denúncias, os temores e os estranhamentos dos engenheiros abriram espaço para índices reveladores daquilo que o projeto da EFMM negava: a existência histórica de sociedades humanas organizadas na floresta.

Data de submissão: 10/09/2020

Data de aceite: 23/02/2021

${ }^{37}$ FORTE, . Do Rio de Janeiro ao Amazonas e Alto Madeira...op. cit. pp. 77-79. 


\section{Referências Bibliográficas}

AMOROSO, Marta Rosa. Guerra mura no século XVIII: versos e versões: representações dos Mura no imaginário Colonial. Campinas, Universidade Estadual de Campinas, dissertação de mestrado em Antropologia, SP, 1991.

BALESTRA, Aline Alcarde. O que significa ser "manso"? A selvageria e a civilização sob diferentes perspectivas. In: DOS SANTOS, Gilton Mendes e APARÍCIO, Miguel. Redes Arawa: ensaios de etnologia do Médio Purus. Manaus, EDUA, 2016.

BARBOZA, Edson Holanda Lima. A Hidra Cearense: rotas de retirantes e escravizados entre o Ceará e as fronteiras do Norte. São Paulo, Pontifícia Universidade Católica; Tese de Doutorado em História.

BASTOS, Carlos Augusto de Castro. No Limiar dos Impérios: projetos, circulações e experiências na fronteira entre a Capitania do Rio Negro e a Província de Mainas (17801820). Tese de Doutorado em História Social - USP, São Paulo, 2013.

CÂNDIDO, Tyrone Apollo Pontes. Proletários das secas: arranjos e desarranjos nas fronteiras do trabalho. Fortaleza: Universidade Federal do Ceará, Tese de Doutorado em História, 2015.

CARDOSO, Antonio Alexandre Isidio. Nem sina, Nem acaso: a tessitura das migrações entre a Província do Ceará e o território amazônico. Fortaleza, Universidade Federal do Ceará, Dissertação de Mestrado em História Social, 2011.

FORTE, Ernesto Mattoso Maia. Do Rio de Janeiro ao Amazonas e Alto Madeira. Itinerário e Trabalhos da Comissão de Estudos da Estrada de Ferro do Madeira e Mamoré: Impressões de Viagem por um dos membros da mesma comissão. Rio de Janeiro: Typ. a Vap. de Soares \& Niemeyer, 1885.

FREIRE, José Ribamar Bessa. Da Língua Geral ao Português: para uma História do uso social das línguas na Amazônia. Rio de Janeiro, Tese de Doutorado em Literatura Comparada, Universidade do Estado do Rio de Janeiro, 2003.

FUNES, Eurípedes A. "Nasci nas matas, nunca tive senhor" - História e Memória dos Mocambos do Baixo Amazonas. São Paulo. Universidade de São Paulo; Tese de doutorado em História Social, 1995.

GRANERO, Fernando Santos, BARCLAY, Frederico. La Frontera Domesticada: História econômica y social de Loreto. 1850-2000. Lima: Ed. Pontifica Universidad Católica Del Peru, 2002.

HARDMAN, Francisco Foot. Trem Fantasma: a ferrovia Madeira-Mamoré e a modernidade na selva. São Paulo: Companhia das Letras, 2005.

HARRIS, Mark. Rebellion on the Amazon: The Cabanagem, Race, and Popular Culture in the North of Brazil, 1798-1840. New York, Cambridge University Press, 2010. 
LEAL, Davi Avelino. Direitos e Processos diferenciados de territorialização: os conflitos pelo uso dos recursos naturais no Rio Madeira (1831-1932). Manaus, Universidade Federal do Amazonas, Tese de Doutorado em Sociedade e Cultura da Amazônia, 2013.

MACHADO, Maria Helena P. T. Brasil a vapor: raça, ciência e viagem no século XIX. São Paulo, Universidade de São Paulo; Tese apresentada para o concurso de Livre Docência, 2005.

MARTINS, José de Souza. Fronteira: a degradação do outro nos confins do humano. São Paulo: Contexto, 2009.

OLIVEIRA, João Pacheco de. O Caboclo e o Brabo: Notas sobre duas Modalidades de Força de Trabalho na Expansão da fronteira Amazônia no século XIX. Encontros com a Civilização Brasileira, 1979, v. 10.

PRATT, Mary Louise. Imperial Eyes: travel writing and transculturation. London and New York: Routledge, 1992.

RANGEL, Alberto. Inferno Verde (Scenas e Scenários do Amazonas). Tours: Typografia Arrault e Ca 1927.

SANTOS, Francisco Jorge dos. Nos Confins Ocidentais da Amazônia Portuguesa: mando metropolitano e a prática do poder régio na Capitania do Rio Negro no século XVIII. Manaus: Tese de Doutorado em Sociedade e Cultura na Amazônia, Universidade Federal do Amazonas, 2012.

SANTOS, Gilton Mendes dos e APARÍCIO, Miguel. Redes Arawa: ensaios de etnologia do Médio Purus. Manaus: EDUA, 2016.

VALEN, Gary Van. Indigenous agency in the Amazon: The Mojos in liberal and Rubber-Boom Bolivia. Tucson: The University of Arizona Press, 2013.

WEINSTEIN, Bárbara. A borracha na Amazônia: expansão e decadência, 1850-1920. São Paulo: HUCITEC: Editora da Universidade de São Paulo, 1993. 